\title{
Design study of a movable mask with low beam impedance
}

\author{
Y. Suetsugu, ${ }^{1}$ K. Shibata, ${ }^{1}$ A. Morishige,${ }^{2}$ Y. Suzuki, ${ }^{2}$ and M. Tsuchiya ${ }^{2}$ \\ ${ }^{1}$ High Energy Accelerator Research Organization (KEK), 1-1 Oho, Tsukuba, Ibaraki, 305-0801, Japan \\ ${ }^{2}$ Kinzoku Giken Co. Ltd., 713 Narihira Shake, Ebina, Kanagawa, 243-0424, Japan
}

(Received 12 October 2006; published 31 October 2006)

\begin{abstract}
A novel design of a movable mask (collimator) for high-current accelerators is proposed. The mask head is supported by a ceramic rod to reduce interference with the beam. One side of the support is coated with a thin $(\sim 1 \mu \mathrm{m})$ conductive material to avoid extra charge up of the head. The head is also made of ceramics to avoid direct damage from an intense beam. To investigate the availability of the new movable mask, the rf properties, such as the impedances of trapped modes and the loss factors, were evaluated by simulation codes. The frequencies and the $\mathrm{Q}$ values of the trapped modes were also measured using a test model, and compared with calculated ones. Two trial modes for KEKB are being manufactured, and will be tested with beams next year.
\end{abstract}

DOI: 10.1103/PhysRevSTAB.9.103501

PACS numbers: 29.20.Dh, 29.27.Bd

\section{INTRODUCTION}

A movable mask (or collimator) is a special vacuum component for particle accelerators to cut off spent particles around a nominal beam orbit, and then to decrease the background noise of the particle detector [1-7]. The movable mask is an indispensable vacuum component for high luminosity machines, such as various factories at present or in the future [8-17].

The movable mask has a head (a block of metal with several radiation lengths) just near the beam orbit, the position of which is remotely adjusted. The movable mask, therefore, has inherently a high beam impedance [1-7,13-20]. Actually, the present movable masks have caused excess heating of adjacent vacuum components, such as the bellows chambers, gate valves, and pump elements, due to the excited higher order modes (HOM) [8-11]. Of course, the present structure was designed to reduce HOM excitation by using a long gentle slope adjacent to the mask head. The loss factors, however, are typically near to $1 \times 10^{12} \mathrm{VC}^{-1}$ [5]. One solution to cure the heating problem is to install a HOM absorber system near the movable masks $[19,20]$. However, if the loss factor of a movable mask is $1 \times 10^{12} \mathrm{VC}^{-1}$, for example, the parasitic loss reaches up to $200 \mathrm{~kW}$, where a beam current of $10 \mathrm{~A}$, a bunch number of 5000, and a ring circumference of $3 \mathrm{~km}$ are assumed. To absorb the huge rf power with a wide frequency range is hardly possible with the present technology.

Another problem of the movable mask is damage to the mask head due to direct hitting of the intense beam, where copper or titanium has usually been used as a head material [1-7]. The beam deposits energy in a narrow area of the head, which can melt it. The development of a movable mask with a further reduced beam impedance and a higher resistance against the intense beam is, therefore, a key issue in realizing a high-intensity accelerator in the future [12-18].

Here, we propose a new structure of a movable mask with a low beam impedance for a high-intensity machine. The mask head is supported by a ceramics rod with a thin and low conductive layer at one side, which can reduce the interference between the mask head and the beam. The mask head is a copper-coated ceramics, which has a higher thermal strength compared to the metals usually used so far. A HOM damper ( $\mathrm{SiC}$, silicon carbide) is prepared just near the mask head to absorb extra HOM, that is, trapped modes.

A similar concept had been proposed as an "invisible" electrode for AES (CERN) and DAFNE (INF) [21-23]. A high-resistive material was used as the electrode and the feedthrough there. In our case, on the other hand, the mask head should have a high conductivity, and the support was directly connected to the beam duct. The mask head, furthermore, is just near the beam, unlike the previous electrode. Although the idea to reduce the interference with the beam by using a highly resistive material is the same, the structure of the movable mask proposed here is quite different from that of the electrode.

In the following, the feasibility of the new-type movable mask to high-current accelerators is discussed. The $\mathrm{rf}$ properties of the structure, such as the resonant frequencies, the Q-factors, and the longitudinal/transverse impedances of the trapped modes, and the loss factor of the structure are calculated by simulation codes. The growth rates of the coupled bunch instability under the parameters of the KEK B-factory (KEKB) at KEK and the Super KEKB (an upgrade plan of the present KEKB) are evaluated. A concrete criterion of the resistivity, furthermore, was obtained in our case. A test model of the new movable mask was also manufactured, and the measured rfproperties are compared with those of the simulation. 


\section{BASIC CONCEPT}

The elemental structure of the new mask is presented in Fig. 1. Note that the two ports for antennas in the figure are only for the calculation described later, and the real structure does not have them. The new movable mask has the following features.

(1) The support of the mask head is a ceramic in order to reduce any interference between the mask head and the passing beam. As shown later, an electromagnetic field, which should be trapped around a support otherwise, disappears by using ceramics. One side surface of the support, however, should have a thin conductive coating to avoid any extra charge up of the mask head, since a highly charged head could be a source of unwanted discharges around it. The promising ceramic materials are $\mathrm{Al}_{2} \mathrm{O}_{3}$ [alumina, relative permittivity $\left(\varepsilon_{r}\right)=9.0$ ], BN [boron nitride, $\left.\varepsilon_{r}=4.0\right]$, and so on. The support should be small as much as the structural strength permits.

(2) The mask head is made of ceramics or graphite to avoid damage due to direct hitting of the intense beam. The mask head should have a radiation length of at least about one, in order to absorb enough energy of spent particles so as to shut them out [24]. The ceramic material, $\mathrm{Al}_{2} \mathrm{O}_{3}$, for example, has a radiation length of $76 \mathrm{~mm}$ [25]. If the length of the mask head is $90 \mathrm{~mm}$, the ratio of that to the radiation length is about 1.2, which is almost the same as that used in KEKB (40 mm Ti head, where the radiation length of Ti is $36 \mathrm{~mm}$ [25]). On the other hand, when an intense highenergy beam hits the mask head directly, the deposited energy is likely to cause a groove on the head [6,7]. $\mathrm{Al}_{2} \mathrm{O}_{3}$ has a melting point of over $2000^{\circ} \mathrm{C}$, and is said to be available up to about $1700^{\circ} \mathrm{C}$. The melting point is higher than that of the titanium $\left(1670^{\circ} \mathrm{C}\right)$. The thermal conductivity of $\mathrm{Al}_{2} \mathrm{O}_{3}$ is $25-30 \mathrm{~W} \mathrm{~m}^{-1} \mathrm{~K}^{-1}$, which is comparable to $\mathrm{Ti}\left(19 \mathrm{~W} \mathrm{~m}^{-1} \mathrm{~K}^{-1}\right)$. Graphite $(\mathrm{C})$ is also available up to a higher temperature than $\mathrm{Al}_{2} \mathrm{O}_{3}$. The radiation length of graphite, however, is about $190 \mathrm{~mm}$ [25], and a much longer mask head is required in this case.

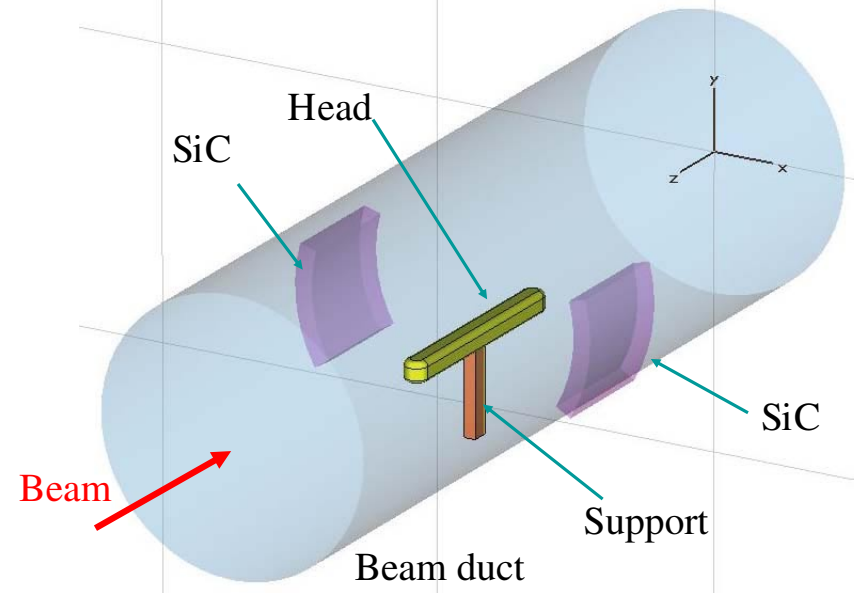

FIG. 1. (Color) Calculation model of a new structure for MWS.
(3) The surface of the mask head should have a high conductivity so as to minimize resistive heating due to the beam, which passes just near the mask head. A copper coating with a thickness of $10 \mu \mathrm{m}$ will be sufficient, since the skin depth of copper at a frequency of $1 \mathrm{GHz}$ is about $2.1 \mu \mathrm{m}$ (the electrical conductivity, $\sigma$, is $5.8 \times$ $10^{7} \Omega^{-1} \mathrm{~m}^{-1}$ ). Since the beam will deposit energy at a deeper level, the copper coating would receive only a small affect even if the beam hits the mask head. Carbon (fiber)type material has an intrinsic electrical conductivity. However, carbon dust can be a problem if it is trapped by a negatively charged beam (i.e., the dust trapping). The dust, furthermore, may be fatal for rf cavities, if the mask is located near to them.

(4) The mask is equipped with HOM absorbers, such as $\mathrm{SiC}$, just near the mask head in order to absorb the extra trapped modes around the mask head. The trapped mode could be a source of discharge near the mask head, heating of the mask head and the support, and also excitation of any beam instability $[1,3,5-7,11]$. The HOM absorber, however, can be a HOM source, itself, and so the quantity of the absorber should be as small as possible.

(5) The mask head and the support are fixed to the mask chamber. The position of the mask head against the beam is adjusted by moving the mask chamber itself $[1,3,5-7]$. The mask chamber has two universal bellows chambers at both sides to absorb the movement to adjust the position.

(6) The input power into the mask head due to the wall current, accompanied by the beam (resistive heating), and HOM of trapped modes, is mainly transferred by radiation to the outside. To improve the efficiency of the radiation, a higher emissivity of the mask head is preferable. The emissivity of a surface can be increased by roughing or blackening of the surface, by oxidation, for example. Another promising way may be a coating of an enameltype layer on the inner surface. An enamel layer will work as a good heat absorption and transfer material as well as HOM absorber. The gas desorption rate, however, should be taken into account for an ultrahigh vacuum use.

\section{CALCULATION OF RF PROPERTIES}

\section{A. Calculation model}

The main purposes of the calculation are as follows.

(1) Define the trapped mode around mask head.

(2) Evaluate the growth rate of the coupled bunch instability due to the trapped modes.

(3) Estimate the tolerable conductivity of a thin layer on the support.

Two simulation codes were used to calculate the rf properties of the structure. One code was MICROWAVE STUDIO 6.0 (MWS, AET Japan). The model is already presented in Fig. 1. The circular beam duct has a diameter of $94 \mathrm{~mm}$, which is a standard size of a normal beam duct of KEKB $[11,26]$. The total length is $400 \mathrm{~mm}$. The mask head has a rectangular solid with a width of $8 \mathrm{~mm}$, a thickness of 
$7 \mathrm{~mm}$ and a length of $90 \mathrm{~mm}$, but all edges are rounded with a radius of $2 \mathrm{~mm}$. In a calculation, the mask head was assumed to be of copper for convenience. The support was $\mathrm{Al}_{2} \mathrm{O}_{3}\left(\varepsilon_{r}=9.0\right)$ with a width of $4 \mathrm{~mm}$, a thickness of $4 \mathrm{~mm}$, and a length of $30 \mathrm{~mm}$, or BN $\left(\varepsilon_{r}=4.0\right)$ with a width of $4 \mathrm{~mm}$, a thickness of $6 \mathrm{~mm}$, and a length of $30 \mathrm{~mm}$. The rf properties described in the next section, however, were almost the same for both support materials. The thickness of the thin conductive layer was $0.1 \mathrm{~mm}$. The length of the antenna inside of the chamber was $10 \mathrm{~mm}$. It was confirmed that the $\mathrm{Q}$ values did not depend on the length of the antenna any more around that length.

By using the MWS, the frequencies $\left(f_{r}\right)$, the Q values $(Q)$, the longitudinal/transverse shunt impedances $\left(R_{S} / R_{T}\right)$ of the trapped modes were calculated by changing the conductivity $(\sigma)$ of the thin layer at one side of the support and the surface area of SiC. In the Mws, the S parameters $\left(S_{11}\right)$ between two ports, as shown in Fig. 1, were calculated using a frequency solver. The calculation method of these parameters is described in Appendix A.

Another code is MAFIA 4.0 (MAFIA, AET Japan). The model for the calculation is presented in Fig. 2. The circular beam duct has a diameter of $47 \mathrm{~mm}$ and a length of $3.2 \mathrm{~m}$. The horizontal and vertical mesh sizes were 2 and $1 \mathrm{~mm}$, respectively. The longitudinal mesh size, on the other hand, was $0.8 \mathrm{~mm}$. The dimensions of the mask head were the same as those in the case of Mws. The support was $\mathrm{Al}_{2} \mathrm{O}_{3}\left(\varepsilon_{r}=9.0\right)$ with a width of $4 \mathrm{~mm}$, a thickness of $4 \mathrm{~mm}$, and a length of $30 \mathrm{~mm}$. The thickness of the thin conductive layer on the support was $0.8 \mathrm{~mm}$, which was limited by the mesh size of the model. The bunch length was changed in the range from 4 to $8 \mathrm{~mm}$. The wake potential was calculated up to $36 \mathrm{~m}$ by the T3 module, that is, in the time domain, and from the direct method.

By using the MAFIA, the frequencies $\left(f_{r}\right)$, the $\mathrm{Q}$ values $(Q)$, the longitudinal/transverse shunt impedances $\left(R_{S} / R_{T}\right)$, and the loss factors $(k)$ were calculated by changing the conductivity $(\sigma)$ of the thin layer, the surface area of $\mathrm{SiC}$, and the bunch length $\left(\sigma_{z}\right)$. The calculation method of these parameters is described in Appendix B.

Two simulation codes were used because the Mws cannot treat the high-energy beam in the calculation first of all.

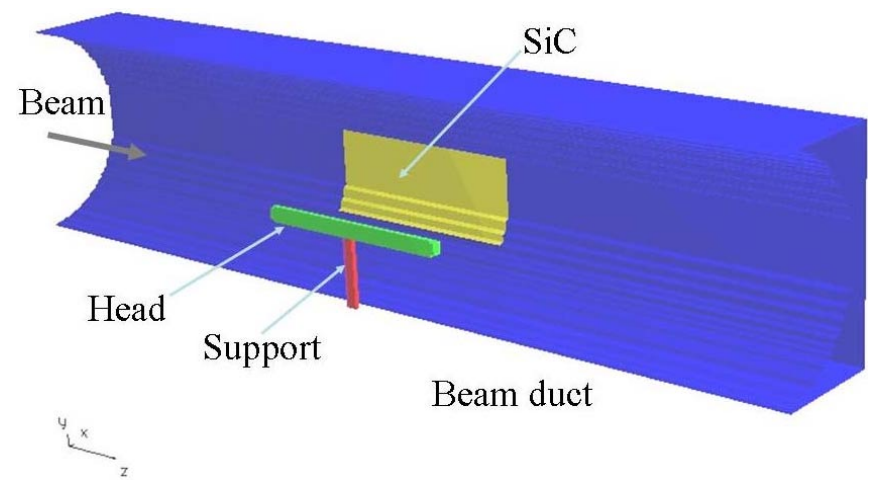

FIG. 2. (Color) Calculation model of a new structure for MAFIA.
The loss factor could not be obtained by Mws. On the other hand, due to the calculation noise and the limited memory of the computer, the calculation of a mode with a high Q value was hardly possible by MAFIA. The two simulation codes were used in a complementary way.

As for the property of the $\mathrm{SiC}$, we used the first-order Debye model for both calculations. In this model, the relative dielectric constant, $\varepsilon_{r}(\omega)$, can be expressed as

$$
\varepsilon_{r}(\omega)=\varepsilon_{\infty}+\frac{\left(\varepsilon_{s}-\varepsilon_{\infty}\right)}{1+i \omega \tau},
$$

where $\varepsilon_{\infty}, \varepsilon_{s}, \tau$ are the infinite value of $\varepsilon_{r}$, the static value of $\varepsilon_{r}$, and the relaxation time, respectively. In the calculation, the values of $\varepsilon_{\infty}=14, \varepsilon_{s}=110$, and $\tau=$ $1 \times 10^{-9} \mathrm{~s}$ were used. These parameters had been used to design the HOM absorbers of the rf cavities for the KEKB [27]; the $\mathrm{SiC}$ with this property is commercially available.

\section{B. Trapped modes}

Two trapped modes were found under the $\mathrm{TE}_{11}$ cutoff frequency of a circular beam pipe with a diameter of $94 \mathrm{~mm}(1.87 \mathrm{GHz})$. Figure 3 shows the frequency spectrum of $S_{11}$ from 0.5 to $2 \mathrm{GHz}$, calculated by MWs for the case of a metal support. One mode had a resonant frequency at about $0.69 \mathrm{GHz}$, where we call it Mode- 1 . The magnetic field of this mode rotates around the support. In other words, the surface current goes up and down along the support. This mode, actually, disappears for a pure ceramic support, that is, for the case of $\sigma=0$. The larger the conductivity, the higher the impedance, as shown later. The mode is that which had caused much trouble in the early versions of the movable masks of KEKB [8-11]. This mode has no problem if a pure ceramic support is adopted. In the present design, however, any conductivity of the support is required to avoid charge up of the mask head, and then the allowable conductivity should be found.

Another mode, here we call it Mode-2, had a frequency of about $1.38 \mathrm{GHz}$. The magnetic field rotates around the

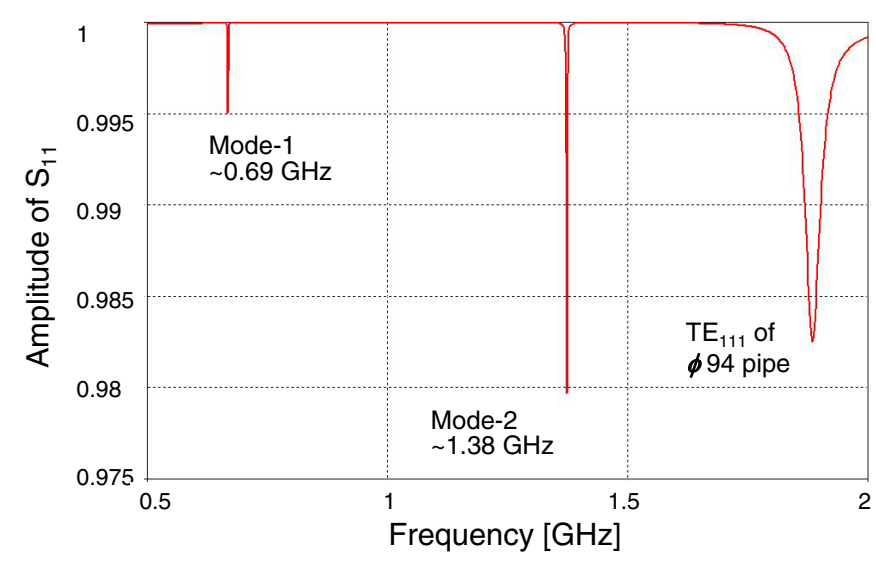

FIG. 3. (Color) Frequency spectrum of $S_{11}$ for a metal support. 
mask head. The current flows backward and forward along the mask head. The mode exists regardless of the conductivity, $\sigma$, that is, for both cases of a metal and a pure dielectric supports. The impedance of this mode, therefore, should be considered in any case.

\section{Shunt impedances $\left(R_{S} / R_{T}\right)$ and $Q$ values $(Q)$}

Figures 4(a) and 4(b) show the dependences of the longitudinal shunt impedance $\left(R_{S}\right)$ and $Q$ on the conductivity $(\sigma)$ of the thin layer on one side of the support calculated by Mws for Mode- 1 and Mode-2, respectively. The upper horizontal axis is the conductivity of the layer $(\sigma)$, but the lower one is the ratio of the skin depth of the layer $(\delta)$ to the thickness $(t), \delta / t$. The skin depth was calculated by the formula

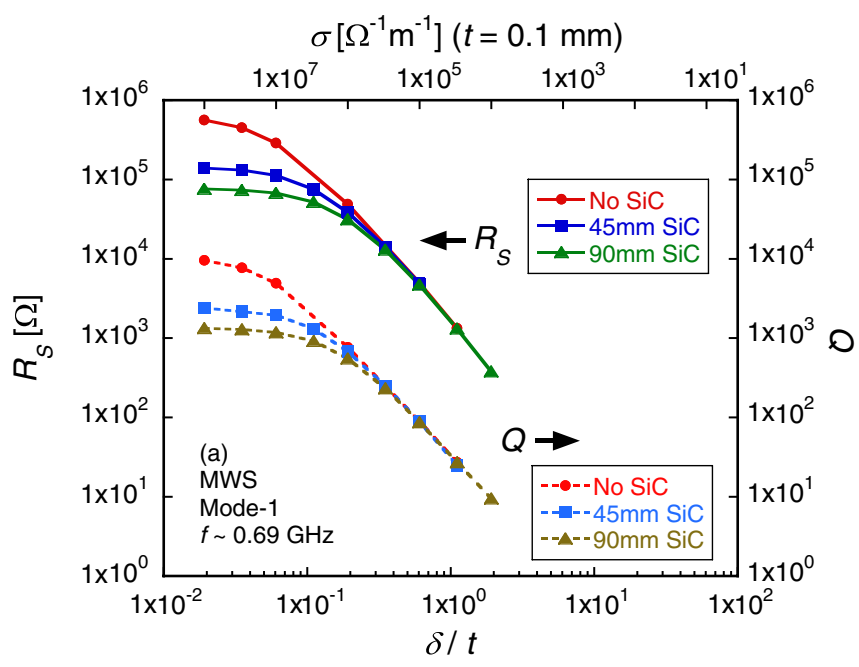

(a)

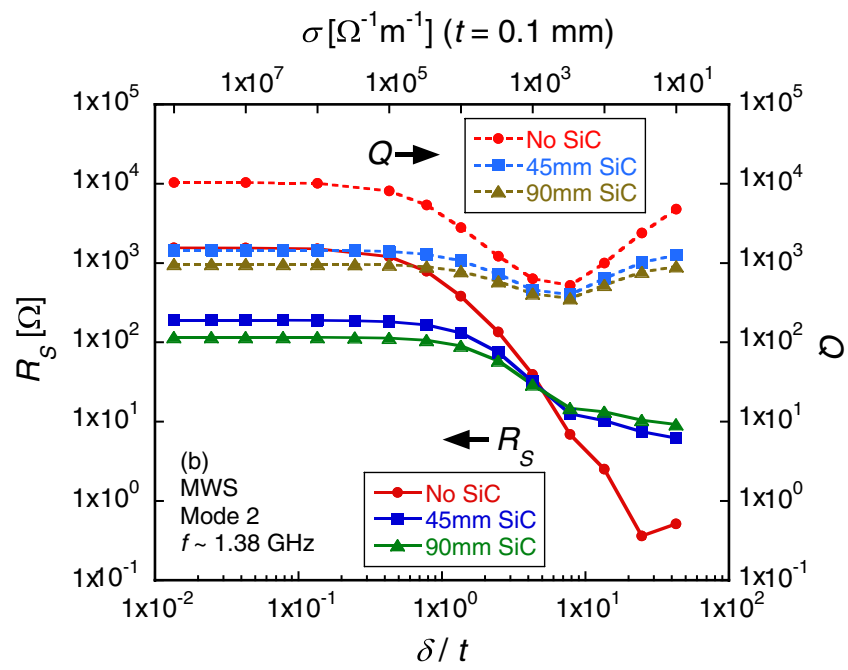

(b)

FIG. 4. (Color) Longitudinal shunt impedance $\left(R_{S}\right)$ and $Q$ of (a) Mode-1 and (b) Mode-2, respectively, as a function of $s$ and $\delta / t$ calculated by MWS. Results are for the cases without $\mathrm{SiC}$, with $\mathrm{SiC}$ of $45^{\circ} \times 45 \mathrm{~mm}$ and $45^{\circ} \times 90 \mathrm{~mm}$.

$$
\delta=\sqrt{\frac{2}{\omega \mu \sigma}}[\mathrm{m}]
$$

where $\omega=2 \pi f, f$ is the frequency $[\mathrm{Hz}], \mu$ is the magnetic permeability in a vacuum $\left(=4 \pi \times 10^{-7}\right)$ and $\sigma$ is the conductivity $\left[\Omega^{-1} \mathrm{~m}^{-1}\right.$ ]; $\delta$ was calculated at the resonant frequency. By using the parameter $\delta / t$, we can discuss the effect of $\sigma$ independently of the real thickness of the layer. The impedances were calculated for three cases, that is, without $\mathrm{SiC}$, and with the $\mathrm{SiC}$ tile (45 and $90 \mathrm{~mm}$ long). The azimuthal occupied angle of the $\mathrm{SiC}$ tile was $45^{\circ}$ for both cases, and the thickness was $10 \mathrm{~mm}$. Two SiC tiles were located at both sides of the chamber, as shown in Fig. 1.

As shown in the figure, the $R_{S}$ of Mode-1 rapidly decreased with increasing $\delta / t$, that is, with decreasing $\sigma$. The $R_{S}$ of Mode-1 was very high, that is, on the order of $10^{5} \Omega$, at $\delta / t<0.1$. Since a region of relatively high resistivity (i.e., large $\delta / t$ ) was concerned here, the $\delta / t$ in the range from 1 to 10 was the main focus. At $\delta / t=1-2, R_{S}=$ $1000-500 \Omega$ and $Q=20-10$, and thus $R_{S} / Q \sim 50$. Mode1 disappears, or weakens, beyond measure for $\delta / t>2$. The effect of $\mathrm{SiC}$ was clear at $\delta / t<0.2$, but the $R_{S}$ and $Q$ values were almost independent to $\delta / t$ for $\delta / t>0.5$.

The $R_{S}$ of Mode- 2 also decreased with increasing $\delta / t$, but did not disappear even for a high $\delta / t$, as shown in Fig. 4(b). The $R_{S}$ of Mode- 2 was on the order of $10^{3} \Omega$ even without $\mathrm{SiC}$, at $\delta / t<0.1$. The behavior of $R_{S}$ against $\sigma$ is similar to that of the loss factor, as shown later. The $Q$, on the other hand, was almost constant regardless of $\delta / t$, except for a dip around $\delta / t \sim 5$. It was found that the power loss in the thin layer (that is, the volume loss in the layer) increased around this condition, and then the $Q$ values decreased. The $Q$ values, actually, varied by changing the volume of the thin layer. The narrower the width, for example, the higher were the minimum $Q$ values, although the dip appeared in any way. The degree of change of the $Q$ value is determined by the percentage of the power loss in the thin layer of the total one. The cause of the clear dip of $Q$ as seen in Fig. 4(b) can be understood by the relatively large volume of the thin conductive layer in the calculation model here $(4 \mathrm{~mm} \times 0.1 \mathrm{~mm})$. In the real case, the volume of the conductive layer will be $1 \mathrm{~mm} \times 1 \mu \mathrm{m}$ or something like that at most, as described later. It is expected, therefore, the change of $Q$ values should be smaller in the actual case than the case here. A high $\sigma$ that satisfies the condition of $\delta / t \sim 5$ will further contribute to decrease the absolute power loss in the thin layer, which makes the $Q$ value high. Actually, the position of the dip of $Q$ shifted to a higher value of $\sigma$ with decreasing a width of the layer. Note that the behavior of $R_{s}$ against $\delta / t$ was not so change even in this case.

Here, based on the above understanding, the $Q$ value was assumed to be a constant with a high value at $\delta / t \ll 1$ (or $\delta / t \gg 1$ ) in the figure. It is also a safe side from a view- 
point of the growth rates of coupled bunch instabilities, as discussed in the next section. Again, $\delta / t$ in the range from 1 to 10 was the main focus. At $\delta / t=1-10, R_{s}=$ $100-10 \Omega$ with $\mathrm{SiC}$, and 500-5 $\Omega$ without $\mathrm{SiC}$, and $Q=$ $\sim 1000$ with $\mathrm{SiC}$ and $\sim 10000$ without $\mathrm{SiC}$. Thus, $R_{S} / Q=$ $0.1-0.01$ with $\mathrm{SiC}$, and $0.05-0.0005$ without $\mathrm{SiC}$.

The resonant frequencies $\left(f_{r}\right)$ varied with $\delta / t$, but the change was within $0.4 \%$ for Mode- 1 and $0.7 \%$ for Mode- 2 ; $f_{r}$ was sensitive to the length of the mask head. In the actual design, $f_{r}$ should not be an integral multiple of the rf frequency used in the accelerator so as to avoid any resonant enhancement of the modes by successive bunches.

For the calculation by MAFIA, on the other hand, the $R_{S}$ of Mode- 1 and Mode- 2 showed almost the same values and behaviors as those by MWS, as shown in Figs. 5(a) and 5(b), respectively. The $Q$ values, however, were smaller than

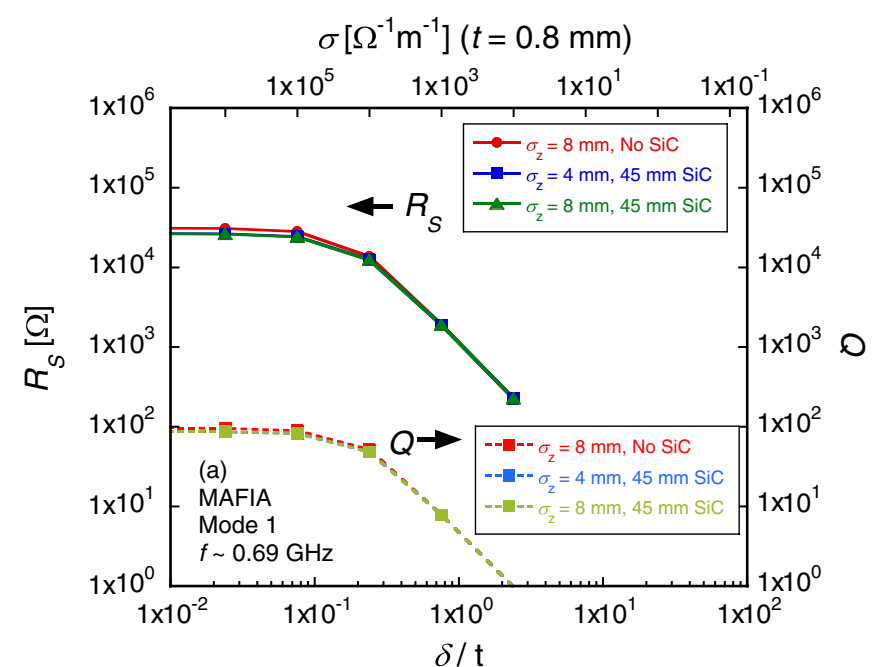

(a)

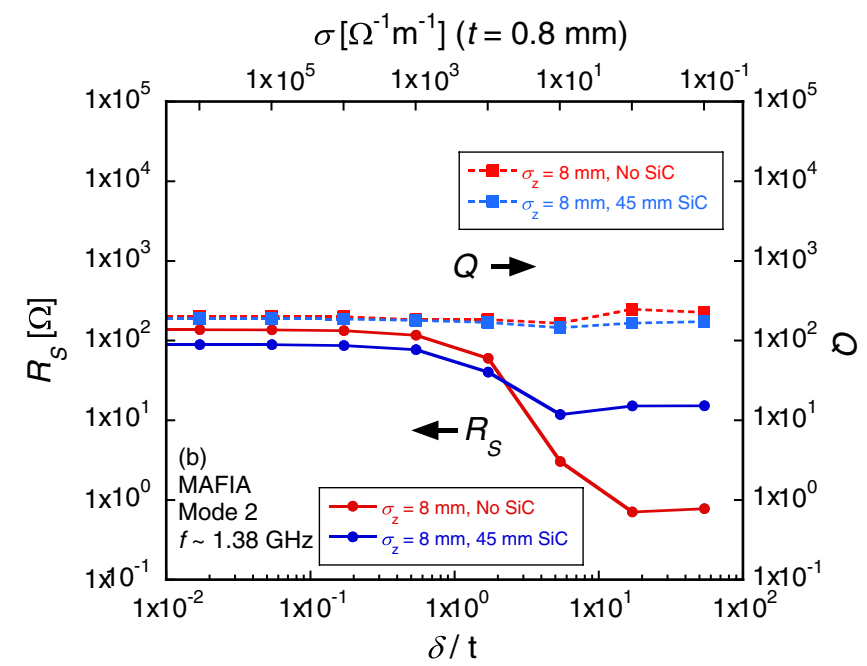

(b)

FIG. 5. (Color) Longitudinal shunt impedance $\left(R_{S}\right)$ and $Q$ of (a) Mode-1 and (b) Mode-2, respectively, as a function of $s$ and $\delta / t$ calculated by MAFIA. Three cases are without $\mathrm{SiC}$, with $\mathrm{SiC}$ of $45^{\circ} \times 45 \mathrm{~mm}$ and $45^{\circ} \times 90 \mathrm{~mm}$. those obtained by Mws by a factor of 3-5. At $\delta / t=1-2$, $R_{S}=1000-200 \Omega$ and $Q=5-1$; thus, $R_{S} / Q \sim 200$. Mode-1 again disappeared, or weakened, beyond measure, for $\delta / t>2$. A similar tendency could be also seen for the case of Mode-2, but the dip of $Q$ was not seen. At $\delta / t=$ $1-10$, as before, $R_{S}=100-10 \Omega$ with $\mathrm{SiC}$, and $100-1 \Omega$ without $\mathrm{SiC}$, and $Q \sim 20$ for both cases; thus, $R_{S} / Q=$ $0.5-0.05$ with $\mathrm{SiC}$, and $0.5-0.005$ without $\mathrm{SiC}$.

The discrepancy of $Q$ between those obtained by MAFIA and Mws was larger for the case where high $Q$ values were obtained in MWS. One reason for the low $Q$ values in the calculation of MAFIA is that damping of the wake potential was insufficient even for a calculation length up to $36 \mathrm{~m}$. The calculation noise, however, became not negligible for calculations with a longer length. The dip of $Q$ at around $\delta / t \sim 5$, which was clearly seen in the case of MWS [Fig. 4(b)], was not observed in the case of MAFIA [Fig. 5(b)], as described above. A possible reason for this might be that the $Q$ values were already small. The $f_{r}$ calculated by MAFIA behaved very similarly to that obtained by MWS.

Although the detailed results are not presented here, a similar tendency was obtained for a calculation of the transverse impedance $\left(R_{T}\right)$. The obtained $R_{T}$ and $R_{T} / Q$ values for Mode- 1 and Mode- 2 calculated by MWS and MAFIA are summarized in Table I, together with the $f_{r}, Q$, $R_{S}$, and $R_{S} / Q$ values described above.

\section{Growth rate of a coupled bunch instability}

Since the impedances of the new structure were the narrow band ones, as expected from $Q$ in Table I (and in Fig. 13, as shown later), a great concern was paid to the coupled-bunch instability (CBI) caused by the modes. The growth rates, $\tau^{-1}\left[\mathrm{~s}^{-1}\right]$, of the longitudinal and transverse CBI were calculated with the formulas presented in Appendix $\mathrm{C}$ using the impedances obtained above. Here, the $\tau^{-1}$ values for the cases of the present KEKB and the Super KEKB, an upgrade plan of KEKB [14,16,28], were evaluated. The main beam parameters (design values) of KEKB and Super KEKB related to the CBI are given in Table II. For both cases, uniform bunch-filling pattern was assumed, i.e., bunches were all of rf buckets, as the worst case.

\section{Longitudinal CBI}

For the case of KEKB, since the damping time is about $20 \mathrm{~ms}, \tau^{-1}$ of the longitudinal CBI should be less than about $50 \mathrm{~s}^{-1}$ at a beam current of $2.6 \mathrm{~A}$. The $\tau^{-1}$ value is in proportion to the beam current (see Appendix C). If the number of movable masks is assumed to be 16 ( 8 of vertical and 8 of horizontal masks), the $\tau^{-1}$ value per one movable mask should be less than $3 \mathrm{~s}^{-1}(\sim 50 / 16)$ in the worst condition.

For the case of Super KEKB, on the other hand, the damping time is about $30 \mathrm{~ms}$, and thus the allowable $\tau^{-1}$ is 
TABLE I. Summary of calculated $f_{r}, Q, R_{S}, R_{S} / Q, R_{T}$, and $R_{T} / Q$.

\begin{tabular}{|c|c|c|c|c|}
\hline & \multicolumn{2}{|c|}{$\begin{array}{c}\text { Mode } 1 \text { at } \delta / t=1-2 \\
\text { (Disappears for } \delta / t>2 \text { ) }\end{array}$} & \multicolumn{2}{|c|}{$\begin{array}{l}\text { Mode } 2 \text { at } \delta / t=1-10 \\
*(Q \text { values at } \delta / t \ll 1)\end{array}$} \\
\hline & MWS & MAFIA & MWS & MAFIA \\
\hline$f_{r}[\mathrm{GHz}]$ & 0.686 & 0.683 & 1.374 & 1.344 \\
\hline$Q$ & $20-10$ & $5-1$ & $\begin{array}{c}\sim 1000(\text { with } \mathrm{SiC}) * \\
\sim 1 \times 10^{4}(\text { without } \mathrm{SiC}) *\end{array}$ & $\begin{array}{l}\sim 200 \text { (with } \mathrm{SiC} \text { ) } \\
\sim 200 \text { (without } \mathrm{SiC} \text { ) }\end{array}$ \\
\hline$R_{S}[\Omega]$ & $1000-500$ & $1000-200$ & $\begin{array}{l}100-10 \text { (with } \mathrm{SiC}) \\
500-5 \text { (without } \mathrm{SiC})\end{array}$ & $\begin{array}{l}100-10 \text { (with SiC) } \\
100-1 \text { (without SiC) }\end{array}$ \\
\hline$R_{S} / Q$ & 50 & 200 & $\begin{array}{c}0.1-0.01 \text { (with } \mathrm{SiC}) \\
\left.0.05-5 \times 10^{-4} \text { (without } \mathrm{SiC}\right)\end{array}$ & $\begin{array}{c}0.5-0.05 \text { (with } \mathrm{SiC}) \\
0.5-0.005 \text { (without } \mathrm{SiC} \text { ) }\end{array}$ \\
\hline$R_{T}\left[\Omega \mathrm{m}^{-1}\right]$ & $\begin{array}{l}2 \times 10^{5}- \\
1 \times 10^{5}\end{array}$ & $\begin{array}{r}5 \times 10^{5}- \\
1 \times 10^{5}\end{array}$ & $\begin{array}{c}\left.1 \times 10^{4}-1000 \text { (with } \mathrm{SiC}\right) \\
\left.1 \times 10^{5}-1000 \text { (without } \mathrm{SiC}\right)\end{array}$ & $\begin{array}{c}\left.1 \times 10^{4}-1000 \text { (with } \mathrm{SiC}\right) \\
\left.2 \times 10^{4}-200 \text { (without } \mathrm{SiC}\right)\end{array}$ \\
\hline$R_{T} / Q$ & $1 \times 10^{4}$ & $1 \times 10^{5}$ & $\begin{array}{c}10-1 \text { (with } \mathrm{SiC}) \\
10-0.1 \text { (without } \mathrm{SiC})\end{array}$ & $\begin{array}{c}50-5 \text { (with } \mathrm{SiC}) \\
100-1 \text { (without } \mathrm{SiC})\end{array}$ \\
\hline
\end{tabular}

about $30 \mathrm{~s}^{-1}$ at a beam current of $9.4 \mathrm{~A}$. Converting the $\tau^{-1}$ to the case of KEKB for convenience, the growth rate should be less than $1 \mathrm{~s}^{-1}$ at a beam current $2.6 \mathrm{~A}$ per one movable mask. Thus, the $\tau^{-1}$ of $1 \mathrm{~s}^{-1}$ was taken as a tolerable growth rate here.

Figures 6(a) and 6(b) show the dependence of $\tau^{-1}\left[\mathrm{~s}^{-1}\right]$ on the longitudinal shunt impedance, $R_{S}$, at a beam current of $2.6 \mathrm{~A}$, calculated using the parameters of KEKB for Mode-1 and Mode-2, respectively. The $\tau^{-1}$ value is the maximum at around the resonant frequencies within a range of $0.1 \mathrm{GHz}$. The $\tau^{-1}$ values of Mode-1 were calculated for two cases of $R_{S} / Q=50$ and 500, and those of Mode-2 were calculated for three cases of $R_{S} / Q=1,0.1$, and 0.01 . The ranges of $R_{S} / Q$ correspond to those presented in Table I. The $\tau^{-1}$ value, however, is almost independent on $R_{S} / Q$ at $\delta / t$ larger than $1000 \Omega$ and $10 \Omega$ for Mode- 1 and Mode-2, respectively.

For Mode-1, it is found from Fig. 6(a) that the $R_{S}$ should be less than $500 \Omega$ to achieve $\tau^{-1}$ less than $1 \mathrm{~s}^{-1}$. From Fig. 4(a) (MWS), then, $\delta / t$ should be larger than 2 to achieve an $R_{S}$ less than $500 \Omega$. That is almost the same even in the case of the MAFIA calculation [Fig. 5(a)].

For Mode-2 [Fig. 6(b)], on the other hand, $R_{S}$ should be less than $200 \Omega$ to achieve a $\tau^{-1}$ of $1 \mathrm{~s}^{-1}$. To achieve $R_{S}$, $\delta / t$ should be larger than 3 if $\mathrm{SiC}$ is not prepared, as indicated from Fig. 4(b) (MWS). Mode-2 has no problem if two $\mathrm{SiC}$ tiles with $45^{\circ} \times 90 \mathrm{~mm}$ are prepared as an absorber. From a calculation by MAFIA, Mode- 2 has no problem regardless of $\mathrm{SiC}$ [Fig. 5(b)].

In summary, $\delta / t$ larger than 3 is sufficient to avoid a longitudinal CBI regardless of the quantity of SiC.

\section{Transverse $\mathrm{CBI}$}

A similar discussion can be made about the transverse CBI. The damping time is about 50 turns $\left(\sim 5 \times 10^{-4} \mathrm{~s}\right)$ for Super KEKB at $9.4 \mathrm{~A}$ (see Table II). Thus, $\tau^{-1}$ of the transverse CBI should be less than $35 \mathrm{~s}^{-1}(=1 / 5 \times$ $\left.10^{-4} / 16 / 9.4 \times 2.6\right)$ for the case equivalent to the $\mathrm{KEKB}$ at a beam current of 2.6 A per one movable mask. The $\tau^{-1}$ value of the transverse CBI can be calculated with the

TABLE II. Summary of main beam parameters of KEKB and Super KEKB.

\begin{tabular}{lccc}
\hline \hline & KEKB & Super KEKB \\
\hline Beam current [A] & 2.6 & 3.5 & 9.4 \\
Beam energy [GeV] & & 3016 & \\
Circumference [m] & & $1 \times 10^{5}$ & \\
Revolution frequency [Hz] & & 5120 & \\
Number of rf buckets & $3.39 \times 10^{-4}$ & & $2.7 \times 10^{-4}$ \\
Momentum compaction factor & $2 \times 10^{3}$ & & $3.1 \times 10^{3}$ \\
Synchrotron frequency [Hz] & 43.537 & & 43.545 \\
Betatron tune & 21.5 & 16 & 30 \\
Longitudinal damping time [ms] & 50 & & 50 \\
Transverse damping time [turn] & & & \\
Number of movable masks & & & \\
\hline \hline
\end{tabular}



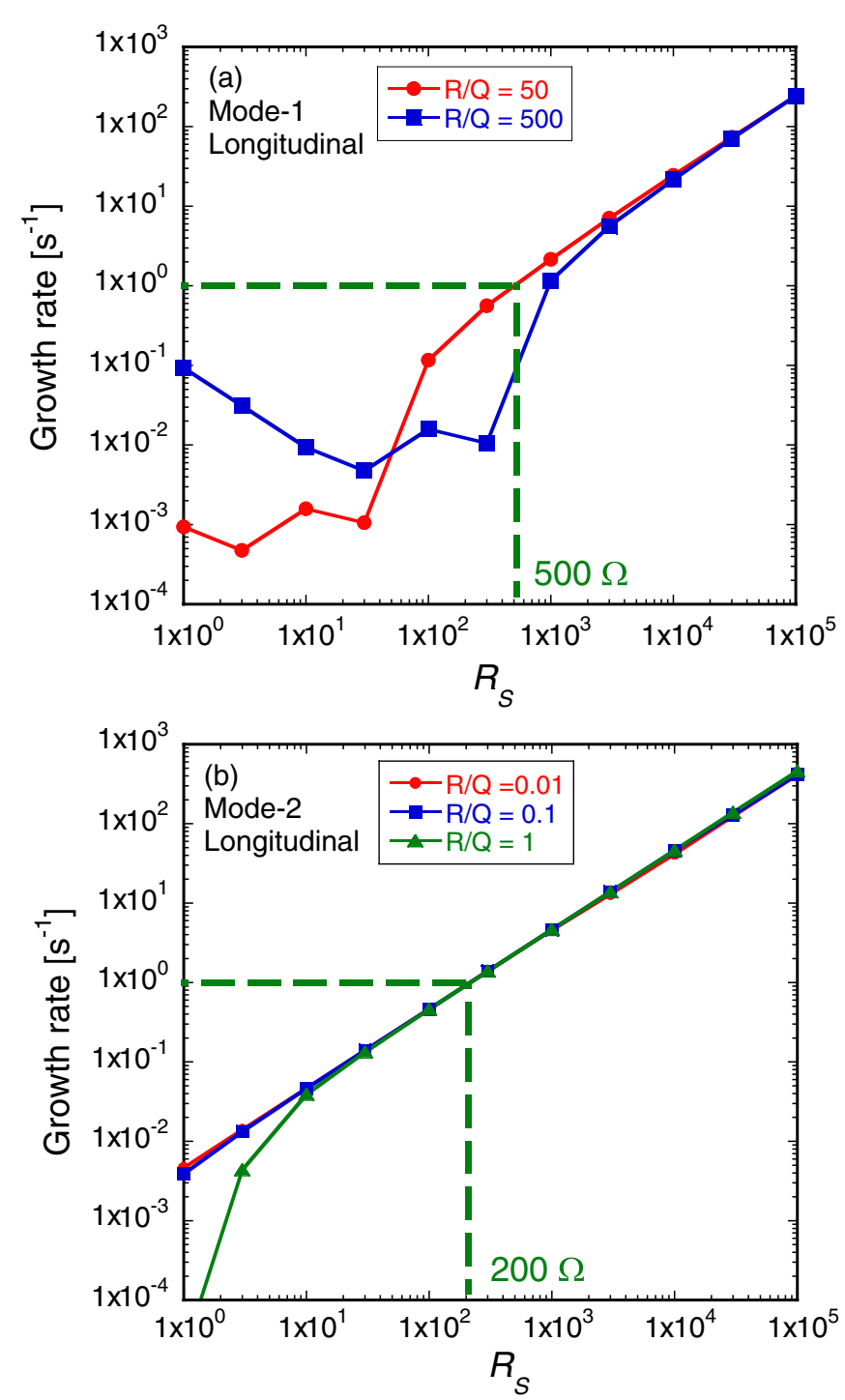

FIG. 6. (Color) Growth rate $\left(\tau^{-1}\right)$ of the longitudinal coupled bunch instability as a function of $R_{S}$ for (a) Mode-1 and (b) Mode-2, respectively. Results are for the cases of $R_{S} / Q=50$ and 500 for Mode- 1 , and $R_{S} / Q=0.01,0.1$, and 1 for Mode-2, respectively.

formulas also indicated in Appendix $\mathrm{C}$, and relations between $\tau^{-1}$ and $R_{T}$ similar to Fig. 6 were obtained in the range of the $R_{T} / Q$ values given in Table I. It was finally found that $R_{T}$ should be less than $2 \times 10^{5} \Omega \mathrm{m}^{-1}$ for both Mode- 1 and Mode- 2 .

As a result, for Mode- $1, \delta / t$ should be larger than 2 from calculations by both MWS and MAFIA. For Mode-2, on the other hand, $\delta / t$ should be larger than 1 if $\mathrm{SiC}$ is not prepared from the calculation by MWS. Any $\delta / t$ is tolerable if two $\mathrm{SiC}$ tiles with $45^{\circ} \times 90 \mathrm{~mm}$ are prepared. Mode- 2 has no problem based on the calculation by MAFIA.

In summary, $\delta / t$ larger than 2 is enough to avoid the transverse CBI regardless of the quantity of $\mathrm{SiC}$. Note here that it is said that the transverse CBI may actually be suppressed to a large degree by a beam-feedback system [16].

\section{Possible Material of a Thin Layer}

Consider the case of a thin layer of $\mathrm{Ti}(\sigma=$ $1.7 \times 10^{6} \Omega^{-1} \mathrm{~m}^{-1}$ ) with a thickness of $1 \mu \mathrm{m}$, for example. The skin depth $(\delta)$ of this layer is $1 \times 10^{-5} \mathrm{~m}$ at a frequency of $1.4 \mathrm{GHz}$. Then $\delta / t$ is 10 , which satisfies the above requirements for both the longitudinal and transverse CBI, that is, $\delta / t>3$. Manufacturing of the thin layer has no problem technically. If the material of the thin layer is TiN, for example, which usually has a higher resistivity than $\mathrm{Ti}$, the condition becomes much safer. If the material is copper $\left(\sigma=5.8 \times 10^{7} \Omega^{-1} \mathrm{~m}^{-1}\right)$ instead of Ti, on the other hand, $\delta / t$ is about 1.8 .

\section{E. Loss factor}

The dependences of the loss factors, $k\left[\mathrm{VC}^{-1}\right]$, of the present movable mask of KEKB (Version 4) and that proposed here on the bunch lengths $\left(\sigma_{z}\right)$ are shown in Fig. 7. The $k$ value was calculated by MAFIA. For the new structure, the loss factors in the cases of a metal support, $\mathrm{Al}_{2} \mathrm{O}_{3}$ support with $\sigma=0$ (pure dielectric) and $10 \Omega^{-1} \mathrm{~m}^{-1}$, were calculated. The $\delta / t$ value corresponds to about 8 for $\sigma=10 \Omega^{-1} \mathrm{~m}^{-1}$ in Mode-1 (see Fig. 5). The gap between the mask head and the beam was $10 \mathrm{~mm}$, which is a typical one at present. The calculated loss factors do not include that of $\mathrm{SiC}$. The $k$ values of the $\mathrm{SiC}\left(45^{\circ} \times 90 \mathrm{~mm}\right)$ were about $5 \times 10^{10} \mathrm{VC}^{-1}$ and $1 \times$ $10^{11} \mathrm{VC}^{-1}$ at bunch lengths of 8 and $4 \mathrm{~mm}$, respectively, for a reference. We note here that the loss factor of $\mathrm{SiC}$ was not also included to the $k$ in the case of the present KEKB

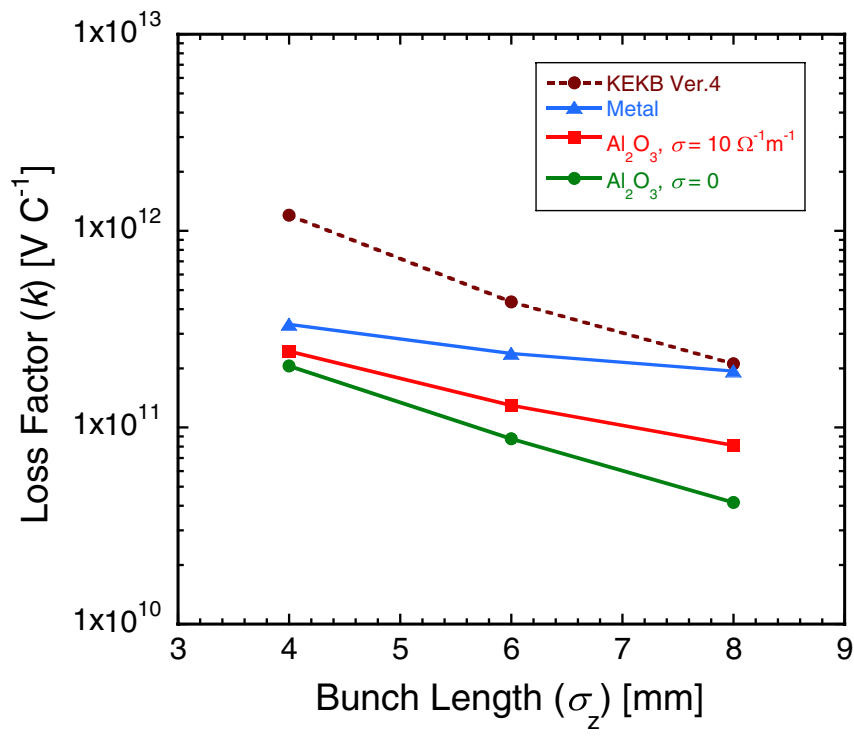

FIG. 7. (Color) Loss factors $(k)$ for the present KEKB movable mask (Version 4), and the new mask structures with a metal support, $\mathrm{Al}_{2} \mathrm{O}_{3}$ supports with $\sigma=0$ and $10 \Omega^{-1} \mathrm{~m}^{-1}$ as a function of bunch length $\left(\sigma_{z}\right)$. 


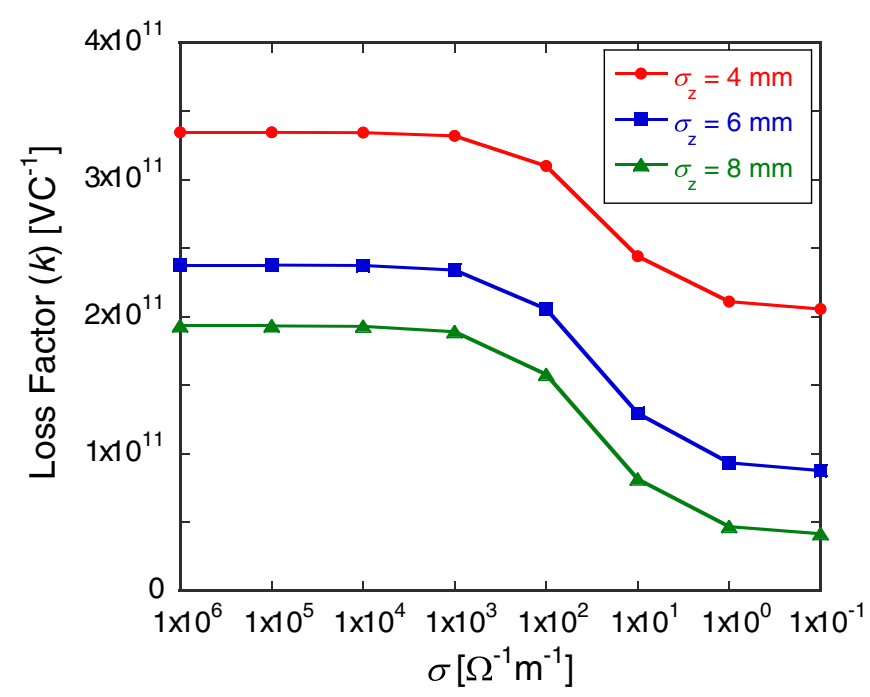

FIG. 8. (Color) Loss factors $(k)$ of the new mask structures as a function of $\sigma$ for $\sigma_{z}=4,6$, and $8 \mathrm{~mm}$.

type. Other extra HOM absorbers, however, were actually required to absorb HOM around the movable mask, as described above $[19,20]$. That is the reason why $\mathrm{SiC}$ was not included in the comparison given here.

The $k$ for the present KEKB design is about $1.2 \times$ $10^{12} \mathrm{VC}^{-1}$ at a bunch length of $4 \mathrm{~mm}$. For the case of the new design, on the other hand, the $k$ value at the same bunch length is $3 \times 10^{11} \mathrm{VC}^{-1}$ for $\sigma=10 \Omega^{-1} \mathrm{~m}^{-1}$ without $\mathrm{SiC}$. The $k$ value is about $1 / 4$ of that of the present structure. The energy loss is, however, still $50 \mathrm{~kW}$, even so at a beam current of $10 \mathrm{~A}$ and a bunch number of 5000 in the KEKB ring. That power may be manageable with the present technology, but a further decrease of $k$ should be necessary by optimizing the alignment and the quantities of $\mathrm{SiC}$, and the structure of mask head, for example.

Note that $k$ increases with decreasing the distance between the mask head and beam. If the distance is $5 \mathrm{~mm}$, instead of $10 \mathrm{~mm}$, for example, the loss factor is $1.5 \times$ $10^{12} \mathrm{VC}^{-1}$. The loss factor almost increases in proportion to the inverse of the distance. This situation is the same as for the preset mask at KEKB.

Figure 8 shows the dependence of $k$ on $\sigma$. With decreasing $\sigma$, in other words, increasing $\delta / t$, the loss factor decreases for $\sigma<1000 \Omega^{-1} \mathrm{~m}^{-1}(\delta / t>1$, see Fig. 5). Compared to Figs. 4(b) and 5(b), the decrease of $k$ corresponds to the decrease of $R_{S}$ of Mode-2, and not that of Mode-1.

\section{F. Estimation of temperature of mask head}

As described above, most of the input power into the mask head is transferred to the outside chamber by radiation. Heat transfer through the ceramic support cannot be expected. The main input power comes from Joule loss by passing bunches, and by the trapped mode. Here, the input power is estimated at first by assuming the case of Super
$\mathrm{KEKB}$, and the expected temperature of the mask head is guessed.

Consider a simple case where a bunch with a length of $\sigma_{z}$ is passing along the center of a circular pipe with a radius of $a[\mathrm{~m}]$. The Joule loss, $P^{\prime}$, at the wall per unit length is given by the following formula: [25]:

$$
P^{\prime}=\frac{\Gamma(3 / 4) I_{b}^{2} C}{4 \pi^{2} a \sigma_{z}^{3 / 2} \sqrt{2 \mu_{r} \sigma_{c} / Z_{0}}}\left[\mathrm{~W} \mathrm{~m}^{-1}\right]
$$

where $I_{b}\left[\mathrm{~A} \mathrm{bunch}{ }^{-1}\right.$ ] is the bunch current, $C[\mathrm{~m}]$ the circumference of the ring, $\mu_{r}$ the relative permeability, $\sigma_{c}\left[\Omega^{-1} \mathrm{~m}^{-1}\right]$ the conductivity of the pipe wall, and $Z_{0}[\Omega]$ the impedance of a vacuum $(=377 \Omega)$. Assuming $I_{b}=10 / 5000=2 \mathrm{~mA}$ bunch $^{-1}, \sigma_{z}=4 \mathrm{~mm}$, $a=10 \mathrm{~mm}, \sigma_{c}=5.8 \times 10^{7} \Omega^{-1} \mathrm{~m}^{-1}$ (copper) and $\mu_{r}=$ 1 , then $P^{\prime}$ is $0.27 \mathrm{~W} \mathrm{~m}^{-1}$. For the case of 5000 bunches in total, the Joule loss is $1.3 \mathrm{~kW} \mathrm{~m}^{-1}$. Then, the input power into the mask head with a length of $90 \mathrm{~mm}$ and a width of $8 \mathrm{~mm}$ at $10 \mathrm{~mm}$ far from the beam, $P_{\text {bunch }}$ [W], is approximately

$$
\begin{aligned}
P_{\text {bunch }} & =1.3 \times 10^{3} \times 90 \times 10^{-3} \times \frac{8}{2 \pi \times 10} \times 2 \\
& \approx 30[\mathrm{~W}],
\end{aligned}
$$

where the last factor of 2 is included, since the wall current flows at the front and back sides of the mask head.

On the other hand, for the trapped modes, only Mode-2 has to be considered, since the Mode- 1 is negligible if $\delta / t \sim 10$, as described above. Generally, the voltage felt by a bunch itself passing in an excited trapped mode, $V_{b}$ [V], can be expressed as [25]

$$
V_{b}=k q=\frac{\omega_{r}}{4}\left(\frac{R_{S}}{Q}\right) q[\mathrm{~V}],
$$

where $k\left[\mathrm{VC}^{-1}\right]$ is the loss factor, $q[\mathrm{C}]$ the bunch charge, and $\omega_{r} 2 \pi \times f_{r}$. If the bunches are in series with an interval of $T$ [s], the effective voltage in total, $V_{\text {eff }}[\mathrm{V}]$, can be obtained by

$$
V_{\text {eff }}=\sum_{n=0}^{\infty} V_{b} \exp \left(-\frac{n T}{Q / \omega_{r}}\right) \cos \left(n T \omega_{r}\right)[\mathrm{V}]
$$

Then, the power loss due to the trapped mode, $P_{\text {mode }}[\mathrm{W}]$, is calculated by

$$
P_{\text {mode }}=V_{\text {eff }} I[\mathrm{~W}]
$$

where $I[\mathrm{~A}]$ is the beam current. Now, using the parameters $\omega_{r}=2 \pi \times 1.38 \mathrm{GH} z, \quad T=2 \mathrm{~ns}, \quad I=10 \mathrm{~A}$, and $q=$ $10 / 1 \times 10^{5} / 5000=2 \times 10^{-8} \mathrm{C}, V_{b}$ is $4.2 \mathrm{~V}$, assuming $R_{S}=10 \Omega$ and $Q=100\left(R_{S} / Q=0.1\right)$. Then, the $V_{\text {eff }}$ is calculated as $2.5 \mathrm{~V}$, and finally $P_{\text {mode }}$ is $25 \mathrm{~W}$ for a $10 \mathrm{~A}$ beam. For reference, if $R_{S}=10 \Omega$ and $Q=1000$ $\left(R_{S} / Q=0.01\right), P_{\text {mode }}$ is $2.2 \mathrm{~W}$. Note here that some fraction of the power will propagate along the pipe, and be 
dissipated by the wall. The $P_{\text {mode }}$ estimated here, therefore, will be somewhat an overestimation.

In summary, the total loss, $P_{\text {in }}$, on the mask head is estimated to be about $30+25 \sim 50 \mathrm{~W}$ for a 10 A beam, including some margin.

Now consider a simple case where heat transfers from an Object-1 inside to a surrounding Object-2. The power transferred from Object-1 to Object-2, $P_{12}$, is given by [25]

$$
P_{12}=\frac{A_{1} \sigma_{s b}\left(T_{1}^{4}-T_{2}^{4}\right)}{\left(\frac{1}{\varepsilon_{1}}+\frac{\left(1-\varepsilon_{2}\right) A_{1}}{\varepsilon_{2} A_{2}}\right)}[\mathrm{W}],
$$

where $A, T$, and $\varepsilon$ are the area, the temperature, and the emissivity of the object, respectively. The suffixes 1 and 2 mean the Object- 1 and Object-2, respectively; $\sigma_{s b}$ is the Stephan-Boltzmann constant, $5.67 \times 10^{-8} \mathrm{~W} \mathrm{~m}^{-2} \mathrm{~K}^{-4}$. In the present case, Object- 1 and Object- 2 correspond to the mask head and the outside chamber, respectively.

If $A_{1}=2.8 \times 10^{-3} \mathrm{~m}^{2}$ (a rectangular of $90 \mathrm{~mm} \times$ $8 \mathrm{~mm} \times 7 \mathrm{~mm}), A_{2}=1.6 \times 10^{-1} \mathrm{~m}^{2}($ a $\phi 94 \mathrm{~mm}$ circular chamber with a length of $500 \mathrm{~mm}), T_{2}=293 \mathrm{~K}\left(20^{\circ} \mathrm{C}\right)$, and $\varepsilon_{1}=\varepsilon_{2}=0.5$ (a rough surface), the temperature of the mask head was estimated to be about $900 \mathrm{~K}$ $\left(\sim 600^{\circ} \mathrm{C}\right)$ for $P_{\text {in }}=50 \mathrm{~W}$. The temperature is not so severe considering the constituent materials being planed here.

Note here that the vapor pressure of $\mathrm{Ti}$ is less than $1 \times$ $10^{-8} \mathrm{~Pa}$ even at $1000 \mathrm{~K}$. Thus, the evaporating rate of $\mathrm{Ti}$ atoms from a surface at $1000 \mathrm{~K}$ is less than about $1 \times$ $10^{12}$ atoms s $\mathrm{s}^{-1} \mathrm{~m}^{-2}$. That is very small compared to the number of atoms at the surface (about $1 \times 10^{19} \mathrm{~m}^{-2}$ ). The $1 \mu \mathrm{m}$ layer of Ti, therefore, will survive for sufficient time even at $1000 \mathrm{~K}$.

Regarding to the thickness of Ti coating, another problem may be the sputtering due to high-energy ions. The operating pressure of the mask is on the order of $1 \times$ $10^{-7} \mathrm{~Pa}$. The surface cannot be directly seen by the beam. Thus, it is expected that the sputtering rate of $\mathrm{Ti}$ by high-energy ions is very small. The lifetime of the layer, in any way, will be checked by the test model.

\section{TEST MODEL}

In order to demonstrate the validity of the calculations so far, and also to check the difficulty level of manufacturing, a test model of the new structure of the atmosphere version was manufactured, as shown in Fig. 9. The chamber was made of aluminum alloy, and the length and the inner radius were 300 and $94 \mathrm{~mm}$, respectively. The mask heads were made of graphite and aluminum alloy. The supports were made of aluminum alloy, $\mathrm{BN}$, and $\mathrm{Al}_{2} \mathrm{O}_{3}$, and can be easily exchanged for tests. At both sides of the chamber, 8 bars of $\mathrm{SiC}$ or aluminum alloy in total were able to be equipped ( 4 bars at each side), as also shown in Fig. 9. The length, the width and the thickness of a bar were 90, 15, and $10 \mathrm{~mm}$, respectively. Two small holes $(\phi 4 \mathrm{~mm})$ were

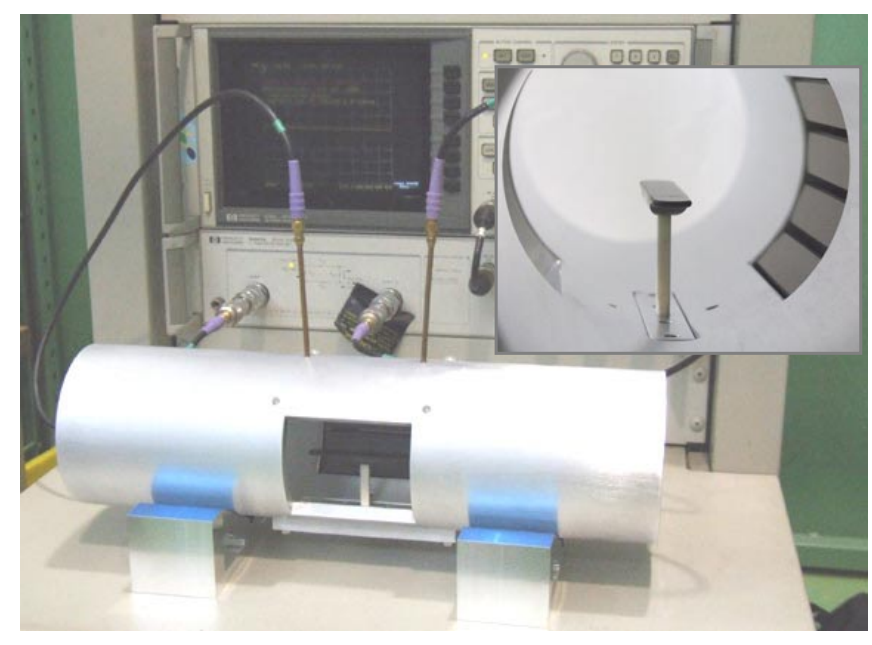

FIG. 9. (Color) Test model of the new mask structure and its inside view.

at the top of the chamber, and two rod antennas of semirigid cables $(\phi 3.2 \mathrm{~mm})$ were inserted, as indicated in Fig. 9. The intruded length of the antennas was about $10 \mathrm{~mm}$. The $\mathrm{S}_{12}$ parameters between these two antennas were measured by a network analyzer (HP Model 8753) while changing the number of the $\mathrm{SiC}$ bars and the support materials. The $\mathrm{Q}$ factors $(Q)$ and the resonant frequencies $\left(f_{r}\right)$ of the trapped modes were evaluated from the measured frequency spectrums of the $S_{12}$ parameters.

\section{A. Manufacturing}

The mask head was successfully made by graphite as well as aluminum alloy, even with a more complex shape than rectangular. A coating by copper was also possible. However, the connection between the graphite head and any ceramic rod had a difficulty. The manufacturing of a $\mathrm{BN}$ support was also possible as well as an $\mathrm{Al}_{2} \mathrm{O}_{3}$ one. We found, however, that the coating of metal, such as Ti, on the surface of BN was not very easy. The coating was possible in principle, but the adhesiveness was very wrong. Thus, at present, the most promising material for both the mask head and the support is $\mathrm{Al}_{2} \mathrm{O}_{3}$.

\section{B. Frequency spectrum}

Figure 10 shows the frequency spectra of $S_{12}$ from 0.4 to $2.0 \mathrm{GHz}$ for the cases of the aluminum support (metal support). As shown in this figure, the two trapped modes, Mode-1 and Mode-2, were clearly observed. Mode-1, however, disappeared for the $\mathrm{BN}$ or $\mathrm{Al}_{2} \mathrm{O}_{3}$ support, as indicated by the calculation (see Fig. 3 for reference).

\section{Effect of SiC bars}

To check the calculated rf properties about trapped modes, the dependences of $Q$ and $f_{r}$ on the number of $\mathrm{SiC}$ bars were measured. Figure 11 shows 6 kinds of 


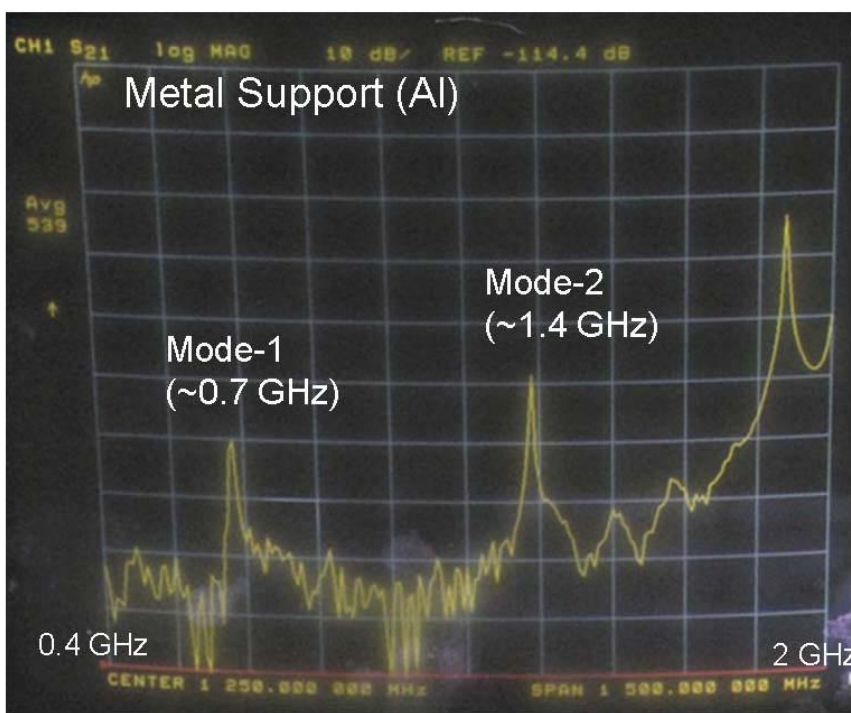

FIG. 10. (Color) Frequency spectrum of $S_{12}$ for aluminum support.
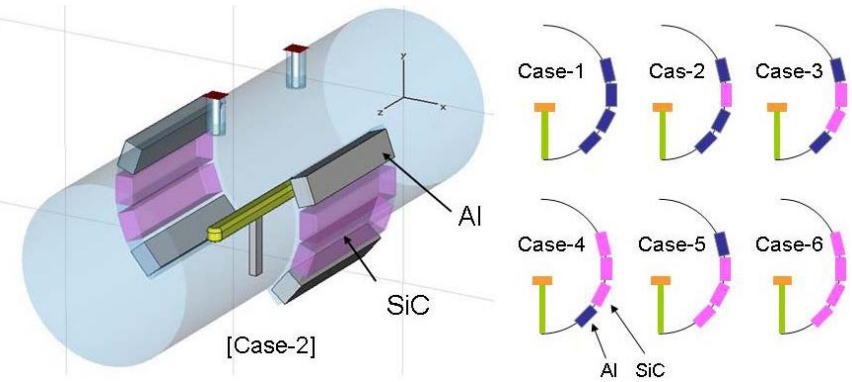

FIG. 11. (Color) Six kinds of configurations of numbers and positions of SiC bars for measurement, from Case-1 to Case-6.

combinations of the numbers and positions of $\mathrm{SiC}$ bars, from Case-1 to Case-6. Figure 12 is an example of the comparison of $f_{r}$ and $Q$ between the calculation and the measurements for Mode-2, where an aluminum support was used. The calculated values were obtained by MWS, since the dependence on $\mathrm{SiC}$ was not obtained by MAFIA, as described above (Fig. 5, for example). The parameters of $\mathrm{SiC}$ were the same as those presented in Sec. III A. The measurements were performed twice.

The measured $f_{r}$ values were in good agreement with the calculated ones for all cases within a discrepancy of $2.5 \%$ for both Mode- 1 and Mode-2. On the other hand, there was a difference in $Q$. For Mode-1, however, the $Q$ values were much lower than the calculated ones, as shown in Fig. 12. The difference of $Q$ for Mode-1 between the measurement and the calculation will be explained by high resistibility at the contact points between the mask head and the support, and/or the support and the chamber. Actually, it is found that the $Q$ value of Mode- 1 was very sensitive to the setting of support, that is, the electric contact between them. For Mode-2, the $Q$ value was in

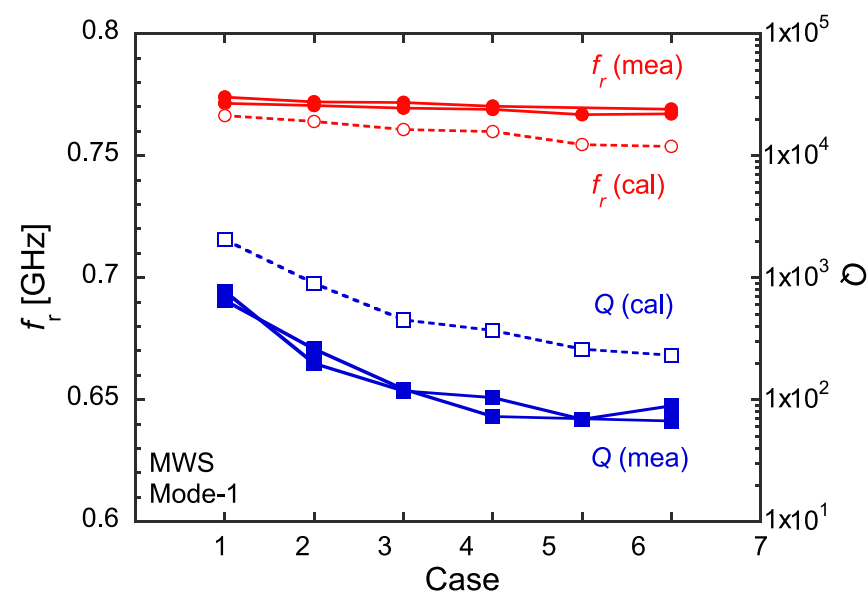

FIG. 12. (Color) Measured (solid lines) and calculated (dotted lines) resonant frequency $\left(f_{r}\right)$ and $\mathrm{Q}$ values $(Q)$ of Mode-1 for 6 cases, from Case-1 to Case-6 in Fig. 11.

good agreement with the calculated one for a factor of 2 at most.

\section{Effect of the conductivity of a thin layer}

To simulate a conductive layer at one side surface of the support, three types of thin metal tapes, that is, a stainlesssteel tape with a thickness of $40 \mu \mathrm{m} \quad(\sigma=1 \times$ $\left.10^{6} \Omega^{-1} \mathrm{~m}^{-1}, \delta / t=0.48\right)$, an aluminum-alloy tape with a thickness of $50 \mu \mathrm{m}\left(\sigma=1 \times 10^{7} \Omega^{-1} \mathrm{~m}^{-1}, \delta / t=\right.$ $0.12)$ and a copper tape with a thickness of $30 \mu \mathrm{m}(\sigma=$ $\left.5 \times 10^{7} \Omega^{-1} \mathrm{~m}^{-1}, \delta / t=0.09\right)$, were attached, and the $Q$ values were measured. As shown in Fig. 13, although the measured Q was smaller than the calculated one (see

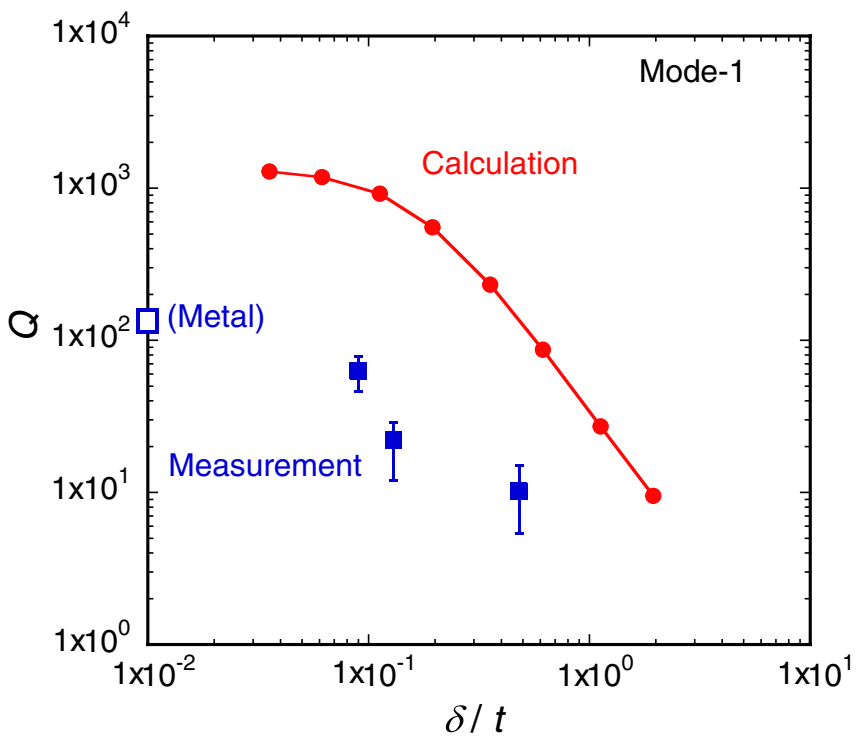

FIG. 13. (Color) Measured and calculated dependence of Q of Mode- 1 on $\delta / t$, where the measurement was performed with three kind of metal tapes. The measured $Q$ for a metal support is also indicated as a reference. 
Fig. 12 for reference), the dependence of $\mathrm{Q}$ on $\delta / t$ was similar to the calculation. Here, the $\mathrm{SiC}$ bars were two, and the calculated results for the case of a $\mathrm{SiC}$ area of $45^{\circ} \times$ $90 \mathrm{~mm}$ in Fig. 4(a) were used for a comparison. The $Q$ value for the case of a metal support is also indicated in Fig. 13 at $\delta / t=1 \times 10^{-2}$ for a reference.

Finally, an $\mathrm{Al}_{2} \mathrm{O}_{3}$ support with a $1 \mu \mathrm{m}$ Ti coating was manufactured for testing, and the $Q$ and the $f_{r}$ values were measured while considering a realistic case. Mode- 1 was not observed as expected. The $f_{r}$ and $Q$ values of Mode-2 were almost the same as the results in Fig. 12. The DC resistively of the support $(30 \mathrm{~mm}$ ) was $86 \Omega$, which should be enough to avoid a charge up of the mask head.

\section{FUTURE PLAN}

Two trial models for the KEKB are being manufactured as a next step. The head is $\mathrm{Al}_{2} \mathrm{O}_{3}$ coated by copper. The support is also $\mathrm{Al}_{2} \mathrm{O}_{3}$ with a Ti or TiN coating on one side surface. The mask head and the support, therefore, will be shaped in one body. Although the SiC tiles may be unnecessary based on the above calculation, two tiles of $\mathrm{SiC}$ with an area of $45^{\circ} \times 90 \mathrm{~mm}$ will be prepared for the trial model for safety. They will be installed in the ring next year, and the performance will be tested with a beam. The temperature of the mask head and the $\mathrm{SiC}$, especially, will be monitored during beam operation.

The structure presented here might be able to be applied to the clearing electrode to mitigate the electron cloud instability in a magnetic field [29]. Different from the case of the ion-clearing electrode [21-23], however, the electrode should be as thin as possible to avoid extra heating due to a high-intensity beam. Some DC voltage, furthermore, should be applied to the electrode in order to act as a clearing electrode, and also to measure the clearing current. The required resistivity of the support (feedthrough) can be estimated using a parameter $\delta / t$, discussed here.

The mask head discussed here should be as parallel as possible to the beam in order to reduce impedance and to be effective as a mask (collimator). For the clearing electrode, on the other hand, the effect of some tilt and/or incline of the electrode on the clearing property may be interesting. The simulation about the clearing electrode is now proceeding [30].

\section{ACKNOWLEDGMENTS}

We would like to express deep thanks to Dr. T. Kageyama, Dr. T. Abe, and Dr. Y. Takeuchi for their kind help with the rf simulation and experiment. We would like to also thank Dr. K. Oide and Dr. K. Kanazawa for their continuous encouragement.

\section{APPENDIX A: CALCULATION BY MWS}

The $f_{r}$ and $Q$ values were obtained from the frequency spectrum of $\mathrm{S}_{11}$. The $f_{r}$ value is that at the top of the resonance curve. The $Q$ value was obtained by $f_{r} / \Delta f_{r}$, where $\Delta f_{r}$ is the half width of the resonance curve. A typical example of the frequency spectrum is shown in Fig. 2.

The longitudinal shunt impedance, $R_{S}[\Omega]$, was calculated by

$$
R_{s}=\frac{V_{z}^{2}}{P_{\text {loss }}}[\Omega],
$$

where $V_{z}$ and the $P_{\text {loss }}$ are the integrated axial ( $z$-direction) electric field along the beam axis, assuming $\beta=1$ and the loss power in the model, respectively, at the resonant frequency. The transit factor was included, and phases of 0 and $\pi / 2$ were considered. The electric field distribution and the power loss could be obtained during the calculation.

The transverse shunt impedance, $R_{T}\left[\Omega \mathrm{m}^{-1}\right]$, was similarly calculated by

$$
\begin{aligned}
R_{T} & =\frac{c}{\omega_{r}} \frac{1}{P_{\text {loss }}}\left(\frac{\Delta V_{z}}{\Delta r}\right)^{2} \\
& =\frac{c}{\omega_{r}} \frac{1}{P_{\text {loss }}}\left(\frac{V_{z}\left(y=y_{1}\right)-V_{z}(y=0)}{y_{1}}\right)^{2}\left[\Omega \mathrm{m}^{-1}\right],
\end{aligned}
$$

where $c$ is the velocity of light $\left(3 \times 10^{8} \mathrm{~ms}^{-1}\right), \omega_{r}=$ $2 \pi f_{r}$ and $y$ is the coordinate in the direction of support. $V_{z}\left(y=y_{1}\right)$ means the integrated axial electric field along a line at $y=y_{1}$. In the actual calculation, $y_{1}$ is set to be $1 \mathrm{~mm}$.

\section{APPENDIX B: CALCULATION BY MAFIA}

The $f_{r}$ and $Q$ values were obtained from the fastFourier-transform (FFT) of the wake potential, that is, the frequency spectrum of the impedance. The longitudinal impedance, $Z_{s}(\omega)[\Omega]$, was obtained by

$$
Z_{s}(\omega)=-\frac{1}{c} \frac{W_{s}(\omega)}{\rho(\omega)}[\Omega],
$$

where $W_{s}(\omega)$ and $\rho(\omega)$ are the FFT of the longitudinal wake potential and that of the bunch profile, respectively. A Gaussian bunch was assumed. A typical example of $Z_{s}$ at $\sigma=1000 \Omega^{-1} \mathrm{~m}^{-1}$ is shown in Fig. 14. The $f_{r}$, the $R_{S}$, and $Q$ values were obtained by fitting the following formula to the calculated $Z_{s}(\omega)$ profile above:

$$
Z_{s}(\omega)=\frac{R_{s} / 2}{1+i Q\left(\frac{\omega_{r}}{\omega}-\frac{\omega}{\omega_{r}}\right)}[\Omega],
$$

where $\omega_{r}=2 \pi f_{r}$.

On the other hand, the transverse impedance, $Z_{T}$ $\left[\Omega \mathrm{m}^{-1}\right]$, is obtained by 


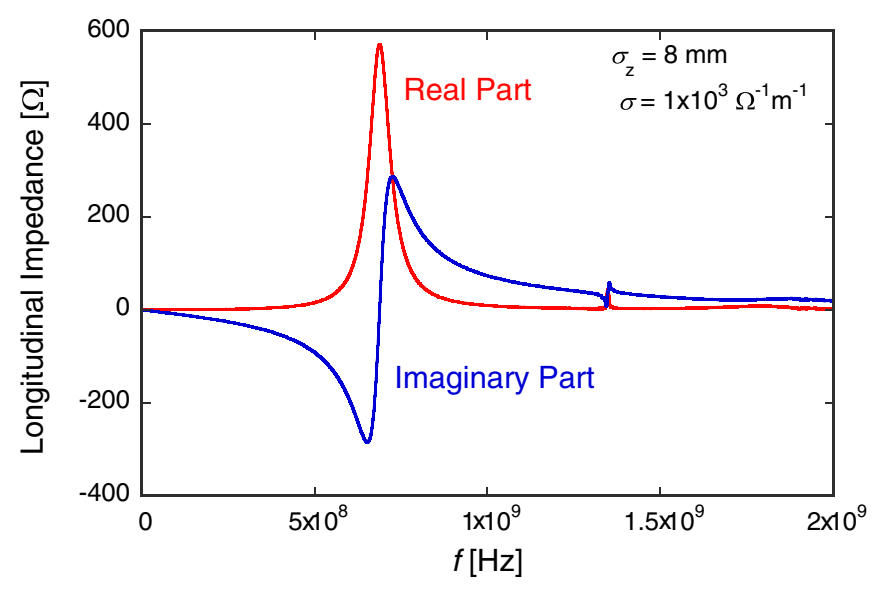

FIG. 14. (Color) An example of longitudinal impedance calculated MAFIA for $\sigma_{z}=8 \mathrm{~mm}$ and $\sigma=1 \mathrm{k} \Omega^{-1} \mathrm{~m}^{-1}$.

$$
Z_{T}(\omega)=i \frac{1}{2 y_{1} c} \frac{W_{T}(\omega)}{\rho(\omega)}\left[\Omega \mathrm{m}^{-1}\right]
$$

where $W_{T}(\omega)$ is the FFT of the transverse wake potential. $y_{1}$ is the offset in the $y$ direction (the direction of support), and is set to be $1 \mathrm{~mm}$ in the calculation. The $f_{r}, R_{T}$, and $Q$ values were obtained by fitting the following formula to the calculated $Z_{T}(\omega)$ profile above, similarly to the case of $Z_{S}(\omega)$ :

$$
Z_{T}(\omega)=\frac{\omega_{r}}{\omega} \frac{R_{T} / 2}{1+i Q\left(\frac{\omega_{r}}{\omega}-\frac{\omega}{\omega_{r}}\right)}\left[\Omega \mathrm{m}^{-1}\right]
$$

In the calculation, two values of $Q$ and $f_{r}$ were obtained for one mode. They were almost the same, but slightly different, and so the average values were used here.

\section{APPENDIX C: CALCULATION OF GROWTH RATE OF COUPLED BUNCH INSTABILITY (CBI) [31]}

\section{Assumption}

(1) Bunches are filled uniformly in all rf buckets.

(2) A bunch has a Gaussian profile.

\section{Longitudinal CBI}

The growth rate, $\tau^{-1}\left[\mathrm{~s}^{-1}\right]$, of the longitudinal CBI is given by

$$
\begin{aligned}
\tau_{\mu}^{-1}= & \frac{e^{2} N M \alpha}{2 T_{0}^{2} E_{0} \omega_{s}} \sum_{p=1}^{\infty}\left\{\omega_{p}^{(\mu)+} \operatorname{Re} Z\left(\omega_{p}^{(\mu)+}\right)\right. \\
& \left.-\omega_{p}^{(\mu)-} \operatorname{Re} Z\left(\omega_{p}^{(\mu)-}\right)\right\}\left[\mathrm{s}^{-1}\right]
\end{aligned}
$$

where

$$
\begin{gathered}
Z(\omega)=\frac{R_{s} / 2}{1+i Q_{0}\left(\frac{\omega_{r}}{\omega}-\frac{\omega}{\omega_{r}}\right)}[\Omega], \\
\omega^{(\mu)+}=\{(p-1) M+\mu\} \omega_{0}+\omega_{s}, \\
\omega^{(\mu)-}=(p M-\mu) \omega_{0}-\omega_{s},
\end{gathered}
$$

and

$Q \mathrm{Q}$ value;

$\omega_{0} 2 \pi \times$ revolution frequency;

$\omega_{r} 2 \pi \times$ resonance frequency $\left(f_{r}\right)$;

$\mu$ mode number;

$e$ electron charge;

$N$ number of particles in a bunch;

$M$ number of bunches;

$T_{0}$ revolution time $[\mathrm{s}]$

$\alpha$ momentum compaction factor;

$E_{0}$ beam energy $[\mathrm{J}] ; \quad \omega_{s} 2 \pi \times$ synchrotron frequency.

\section{Transverse CBI}

The growth rate, $\tau^{-1}\left[\mathrm{~s}^{-1}\right]$, of the transverse CBI is given by

$$
\tau_{\mu}^{-1}=-\frac{e^{2} c N M}{2 T_{0}^{2} E_{0} \omega_{\beta}} \sum_{p=1}^{\infty}\left\{\operatorname{Re} Z_{T}\left(\omega_{p}^{\left(\mu^{\prime}\right)+}\right)-\operatorname{Re} Z_{T}\left(\omega_{p}^{\left(\mu^{\prime}\right)-}\right)\right\}\left[\mathrm{s}^{-1}\right]
$$

where

$$
Z_{T}(\omega)=\frac{\omega_{r}}{\omega} \frac{R_{T} / 2}{1+i Q_{0}\left(\frac{\omega_{r}}{\omega}-\frac{\omega}{\omega_{r}}\right)}\left[\Omega \mathrm{m}^{-1}\right]
$$




$$
\begin{gathered}
\omega^{\left(\mu^{\prime}\right)+} \equiv\left\{(p-1) M+\mu^{\prime}\right\} \omega_{0}+\delta \omega_{\beta}, \quad \omega^{\left(\mu^{\prime}\right)-} \equiv\left(p M-\mu^{\prime}\right) \omega_{0}-\delta \omega_{\beta} \\
\mu^{\prime} \equiv \mu+N_{\beta}, \quad \omega_{\beta}=N_{\beta} \omega_{0}+\delta \omega_{\beta},
\end{gathered}
$$

and

$$
\begin{array}{ll}
R_{T} \text { shunt impedance }\left[\Omega \mathrm{m}^{-1}\right] ; & Q \mathrm{Q} \text { value; } \\
\omega_{0} 2 \pi \times \text { revolution frequency; } & \omega_{r} 2 \pi \times \text { resonance frequency }\left(f_{r}\right) ; \\
\mu \text { mode number; } & e \text { electron charge; }
\end{array}
$$

$N$ number of particles in a bunch;

$M$ number of bunches; $\quad T_{0}$ revolution time [s];

$\alpha$ momentum compaction factor;

$E_{0}$ beam energy $[\mathrm{J}] ; \quad \omega_{\beta} 2 \pi \times$ betatron frequency.

[1] N. Akasaka, T. Kageyama, Y. Suetsugu, and Y. Takeuchi, Proceedings of EPAC2000, Vienna, p. 2301.

[2] J. Seeman, S. DeBarger, S. Metcalfe, M. Nordby, and C. Ng, Proceedings of EPAC2000, Vienna, p. 2298.

[3] Y. Suetsugu, N. Akasaka, T. Kageyama, Y. Takeuchi, K. Kanazawa, and K. Satoh, Proceedings of PAC2001, Chicago, p. 2186.

[4] S. Debarger, S. Metcale, C. Ng, T. G. Porter, J. Seeman, M. Sullivan, and U. Wienands, Proceedings of HEACC2001, Tsukuba, 2001, http://conference.kek.jp/heacc2001/.

[5] K. Shibata, Y. Suetsugu, and T. Kageyama, Proceedings of PAC2003, Portland, p. 800.

[6] Y. Suetsugu, K. Shibata, T. Sanami, T. Kageyama, and Y. Takeuchi, Rev. Sci. Instrum. 74, 3297 (2003).

[7] Y. Suetsugu, T. Kageyama, K. Shibata, and T. Sanami, Nucl. Instrum. Methods Phys. Res., Sect. A 513, 465 (2003).

[8] Y. Funakoshi et al., Proceedings of PAC2001, Chicago, p. 3546.

[9] H. Koiso et al., Proceedings of EPAC2002, Paris, p. 341.

[10] K. Akai et al., Nucl. Instrum. Methods Phys. Res., Sect. A 499, 191 (2003).

[11] Y. Suetsugu, K. Kanazawa, S. Kato, H. Hisamatsu, M. Shimamoto, and M. Shirai, J. Vac. Sci. Technol. A 21, 1436 (2003).

[12] Y. Suetsugu, K. Shibata, and K. Kanazawa, Proceedings of PAC2003, Portland, p. 806.

[13] Y. Suetsugu, Proceedings of PAC2003, Portland, p. 612.

[14] Y. Suetsugu, K. Kanazawa, K. Shibata, N. Ohuchi, H. Hisamatsu, and M. Shirai, Proceedings of PAC2005, Knoxville, p. 3256.

[15] J. Frisch, E. Doyle, and K. Skarpaas, Proceedings of PAC2001, Chicago, p. 1258.

[16] SuperKEKB Task Force, KEK Report 2004-4, 2004, p. 465.
[17] A. Mikhailichenko, Proceedings of EPAC2006, Edinburgh, p. 807.

[18] I. Zagorodnov and K.L.F. Bane, Proceedings of EPAC2006, Edinburgh, Scotland, p. 2859.

[19] Y. Suetsugu, T. Kageyama, Y. Takeuchi, and K. Shibata, Nucl. Instrum. Methods Phys. Res., Sect. A 533, 295 (2004).

[20] Y. Suetsugu, T. Kageyama, Y. Takeuchi, and K. Shibata, Proceedings of PAC2003, Portland, p. 803.

[21] S. Bartalucci, J. F. Bottoilier, R. Cappi, F. Caspers, J. P. Delahaya, B. Frammery, K. Hübnet, A. Krusche, A. Poncet, and L. Rivkin, Proceedings of PAC'87, Washington, D.C., p. 1234.

[22] F. Caspers, in ECLOUD02, 2002, CERN.

[23] M. Spataro and M. Zobov, DAFNE Technical Note, INFNLFN, G-64, 2005.

[24] J. Haba, KEK (BELLE Group) (private communication).

[25] A. W. Chao and M. Tigner, Handbook of Accelerator Physics and Engineering (World Scientific, Singapore, 1999).

[26] K. Kanazawa, S. Kato, Y. Suetsugu, H. Hisamatsu, M. Shimamoto, M. Sato, and M. Shirai, Appl. Surf. Sci. 169, 715 (2001).

[27] Y. Takeuchi, K. Akai, N. Akasaka, E. Ezura, T. Kageyama, H. Mizuno, F. Naito, H. Nakanishi, Y. Yamazaki, and T. Kobayashi, Proceedings of EPAC'96, Sitges, p. 2020.

[28] Home page of Super KEKB, http://www-kekb.kek.jp/ SuperKEKB/home.html.

[29] L. Wang, H. Fukumab, S. Kurokawab, M. Pivi, and G. Xiac, Proceedings of EPAC2006, Edinburgh (TUPLS003).

[30] Y. Suetsugu and K. Shibata, in ILCDR06 (ILC Damping Ring R\&D Workshop), 2006, Cornell University.

[31] For example, A. W. Chao, Physics of Collective Beam Instabilities in High Energy Accelerators (John Wiley \& Sons, Inc., New York, 1993). 